Hua-Li Jia*, Juan Zhou, Xin Wang, Hui Zhao and Bo-Fang Feng

\title{
The crystal structure of 2-bromoisonicotinic acid, $\mathrm{C}_{6} \mathrm{H}_{4} \mathrm{BrNO}_{2}$
}

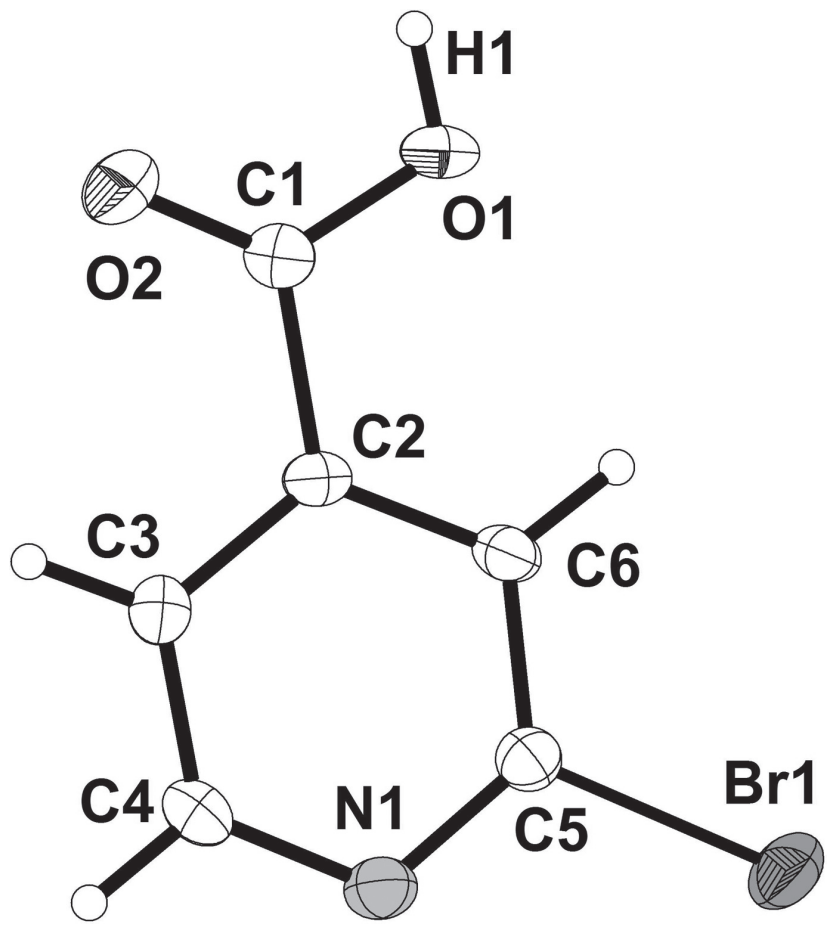

https://doi.org/10.1515/ncrs-2019-0798

Received October 28, 2019; accepted December 28, 2019; available online January 25,2020

\footnotetext{
Abstract

$\mathrm{C}_{6} \mathrm{H}_{4} \mathrm{BrNO}_{2}$, monoclinic, $P 2_{1} / c$ (no. 14), $a=11.9715(14) \AA$, $b=7.5753(7) \AA, \quad c=7.4498(8) \AA, \quad \beta=102.302(4)^{\circ}$, $V=660.09(12) \AA^{3}, Z=4, R_{\mathrm{gt}}(F)=0.0290, w R_{\mathrm{ref}}\left(F^{2}\right)=0.0635$, $T=150(2) \mathrm{K}$.
}

\section{CCDC no.: 1974534}

The molecular structure is shown in the figure. Table 1 contains crystallographic data and Table 2 contains the list of the atoms including atomic coordinates and displacement parameters.

\footnotetext{
*Corresponding author: Hua-Li Jia, School of Chemistry and Chemical Engineering, Zhoukou Normal University, Zhoukou, Henan Province 466001, P.R. China, e-mail: jiahualiwhu@163.com. https://orcid.org/0000-0003-2702-3272

Juan Zhou, Xin Wang, Hui Zhao and Bo-Fang Feng: School of Chemistry and Chemical Engineering, Zhoukou Normal University, Zhoukou, Henan Province 466001, P.R. China
}

Ø Open Access. ( 2020 Hua-Li Jia et al., published by De Gruyter. (c) BY License.
Table 1: Data collection and handling.

\begin{tabular}{ll}
\hline Crystal: & Colourless \\
Size: & $0.25 \times 0.15 \times 0.10 \mathrm{~mm}$ \\
Wavelength: & Mo $K \alpha$ radiation $(0.71073 \AA)$ \\
$\mu:$ & $6.15 \mathrm{~mm}^{-1}$ \\
Diffractometer, scan mode: & Bruker APEX-II, $\varphi$ and $\omega$ \\
$\theta_{\text {max }}$, completeness: & $26.4^{\circ},>99 \%$ \\
$N(h k l)_{\text {measured }}, N(h k l)_{\text {unique }}, R_{\text {int }}:$ & $8662,1354,0.058$ \\
Criterion for $I_{\text {obs }}, N\left(h k l_{\text {gt }}:\right.$ & $I_{\text {obs }}>2 \sigma\left(I_{\text {obs }}\right), 1106$ \\
$N(\text { param })_{\text {refined }}:$ & 92 \\
Programs: & Bruker [1], SHELX [2], Olex2 [3, 4] \\
\hline
\end{tabular}

Table 2: Fractional atomic coordinates and isotropic or equivalent isotropic displacement parameters $\left(\AA^{2}\right)$.

\begin{tabular}{lrrrr}
\hline Atom & $\boldsymbol{x}$ & $\boldsymbol{y}$ & $\boldsymbol{z}$ & $\boldsymbol{U}_{\text {iso }}{ }^{*} \boldsymbol{U}_{\text {eq }}$ \\
\hline Br1 & $0.45682(3)$ & $0.20988(4)$ & $0.56170(5)$ & $0.02182(12)$ \\
C1 & $0.1845(3)$ & $0.7529(4)$ & $0.6430(4)$ & $0.0192(7)$ \\
C2 & $0.2045(3)$ & $0.5562(4)$ & $0.6335(4)$ & $0.0166(7)$ \\
C3 & $0.1205(3)$ & $0.4401(4)$ & $0.6635(4)$ & $0.0195(7)$ \\
H3 & $0.0509(3)$ & $0.4828(4)$ & $0.6892(4)$ & $0.0234(8)^{\star}$ \\
C4 & $0.1405(3)$ & $0.2614(4)$ & $0.6551(5)$ & $0.0207(7)$ \\
H4 & $0.0824(3)$ & $0.1818(4)$ & $0.6725(5)$ & $0.0248(8)^{\star}$ \\
C5 & $0.3180(3)$ & $0.3086(4)$ & $0.5988(4)$ & $0.0160(6)$ \\
C6 & $0.3057(3)$ & $0.4902(4)$ & $0.5985(4)$ & $0.0166(7)$ \\
H6 & $0.3641(3)$ & $0.5664(4)$ & $0.5753(4)$ & $0.0200(8)^{\star}$ \\
N1 & $0.2385(2)$ & $0.1946(3)$ & $0.6234(4)$ & $0.0185(6)$ \\
01 & $0.2684(2)$ & $0.8449(3)$ & $0.5986(4)$ & $0.0254(6)$ \\
H1 & $0.2552(17)$ & $0.9532(3)$ & $0.606(5)$ & $0.0380(8)^{*}$ \\
02 & $0.1016(2)$ & $0.8137(3)$ & $0.6875(4)$ & $0.0293(6)$ \\
\hline
\end{tabular}

\section{Source of material}

The title compound, 2-bromoisonicotinic acid (2.01 g, $1 \mathrm{mmol}$ ), was added to $10 \mathrm{~mL}$ THF and stirred for $10 \mathrm{~min}$ under room temperature for $10 \mathrm{~min}$. Then the solution was filtered and let evaporate in air. Many colorless crystals were obtained after 2 days, yield 83.5\% (based on 2-bromoisonicotinic acid).

\section{Experimental details}

The structure was solved by direct methods with the SHELXS program. All H-atoms were positioned with idealized geometry and refined isotropically $\left(U_{\text {iso }}(\mathrm{H})=1.2 U_{\text {eq }}(\mathrm{C})\right.$ and $1.5 U_{\text {eq }}(\mathrm{O})$, for all $\mathrm{H}$ atoms) using a riding model with $\mathrm{C}-\mathrm{H}=0.950-0.951 \AA$ and $\mathrm{O}-\mathrm{H}=0.840 \AA$ ). 


\section{Comment}

Up to now, the crystal structures of halogen substituted isonicotinic acid or their complexes have been reported rarely. To the best of our knowledge, there are only one example of 3-chloroisonicotinic acid [5] and two examples of 3chloroisonicotinic acid based $\mathrm{Cu}(\mathrm{I})$ or $\mathrm{Ag}(\mathrm{I})$ complexes [6, 7] and a related Sn(II) complex [8]. There are also some examples of di-halogen substituted isonicotinic acids such as 3,5dichloroisonicotinic acid, 2,6-dibromoisonicotinic acid and 3,5-dibromoisonicotinic acid [9]. Indeed, it has not been reported any crystal structure of mono-bromoisonicotinic acid or its complexes.

The title compound, 2-aminoisophthalic acid, with the molecule formula of $\mathrm{C}_{6} \mathrm{H}_{4} \mathrm{BrNO}_{2}$, crystallizes in monoclinic, $P 2_{1} / c$ space group. All of the atoms are nearly co-planar, including the hydrogen atoms. The bond length of $\mathrm{C}-\mathrm{Br}$ is $1.8956(36) \AA$, the bond lengths of $\mathrm{C}-\mathrm{C}$ in the ring range from $1.384(4)$ to $1.389(4) \AA$. The two $\mathrm{C}-\mathrm{N}$ are $1.326(4)$ and 1.344(4) A. The single bond of $\mathrm{C}-\mathrm{C}$ is 1.513(4) $\AA$. The two C$O$ bond lengths from carboxyl group are 1.203(4) and 1.321(4), indicating that the shorter is $\mathrm{C}=\mathrm{O}$ bond, and the longer is the $\mathrm{C}-\mathrm{O}$ bond. There are only $\mathrm{O}-\mathrm{H} \cdots \mathrm{N}$ hydrogen bonds, which link adjacent molecules to a one-dimensional supramolecular structure by a head-to-tail mode. All bond lengths and angles of 2-bromoisonicotinic acid are normal and comparable with its analogues.

Acknowledgements: This study was supported by Youth backbone teacher training program in henan province (2019GGJS221), Young and middle-aged backbone teachers plan of Zhoukou Normal University.

\section{References}

1. Bruker. SAINT v8.37A. Bruker AXS Inc, Madison, WI, USA (2015).

2. Sheldrick, G. M.: A short history of SHELX. Acta Crystallogr. A64 (2008) 112-122.

3. Bourhis, L. J.; Dolomanov, O. V.; Gildea, R. J.; Howard, J. A. K.; Puschmann, H.: The anatomy of a comprehensive constrained, restrained refinement program for the modern computing environment - Olex2 dissected. Acta Crystallogr. A71 (2015) 59-75.

4. Dolomanov, O. V.; Bourhis, L. J.; Gildea, R. J.; Howard, J. A. K.; Puschmann, H.: OLEX2: a complete structure solution, refinement and analysis program. J. Appl. Crystallogr. 42 (2009) 339-341.

5. Long, S.; Zhou, P.; Parkin, S.; Li, T.: Polymorphism and solidto-solid phase transitions of a simple organic molecule, 3-chloroisonicotinic acid. CrystEngComm 17 (2015) 2389-2397.

6. Mei, L.; Hu, K.-Q.; Zhang, Z.-H.; An, S.-W.; Chai, Z.-F.; Shi, W.-Q.: Stepwise ortho chlorination of carboxyl groups for promoting structure variance of heterometallic uranyl-silver coordination polymers of isonicotinate. Inorg. Chem. 57 (2018) 4673-4685.

7. Conesa-Egea, J.; Redondo, C. D.; Martinez, J. I.; Gomez-Garcia, C. J.; Castillo, O.; Zamora, F.; Amo-Ochoa, P.: Supramolecular interactions modulating electrical conductivity and nanoprocessing of copper-iodine double-chain coordination polymers. Inorg. Chem. 57 (2018) 7568-7577.

8. Li, Q.; Wang, F.; Zhang, R.; Cui, J.; Ma, C.: Syntheses and characterization of organostannoxanes derived from 2 chloroisonicotinic acid: tetranuclear and hexanuclear. Polyhedron 85 (2015) 361-368.

9. Mei, L.; Wang, C.-Z.; Wang, L.; Zhao, Y.-L.; Chai, Z.-F.; Shi, W.-Q.: Halogen bonded three-dimensional uranyl-organic compounds with unprecedented halogen-halogen interactions and structure diversity upon variation of halogen substitution. Cryst. Growth Des. 15 (2015) 1395-1406. 